Orbis Tertius, vol. XXIII, $\mathrm{n}^{\circ}$ 28, e087, diciembre 2018. ISSN 1851-7811

Universidad Nacional de La Plata

Facultad de Humanidades y Ciencias de la Educación

Centro de Estudios de Teoría y Crítica Literaria

\title{
La disputa del Nuevo Mundo en la prensa periódica porteña hacia fines del Virreinato
}

\section{Pablo Martínez Gramuglia* \\ * Universidad de Buenos Aires, Argentina.}

Cita sugerida: Martínez Gramuglia, P. (2018). La disputa del Nuevo Mundo en la prensa periódica porteña hacia fines del Virreinato. Orbis Tertius, 23(28), e087. https://doi.org/10.24215/18517811e087

(c) (i) (2) Esta obra está bajo licencia Creative Commons Atribución-NoComercial-CompartirIgual 4.0 Internacional http://creativecommons.org/licenses/by-nc-sa/4.0/deed.es AR 


\title{
La disputa del Nuevo Mundo en la prensa periódica porteña hacia fines del Virreinato
}

\author{
por Pablo Martínez Gramuglia \\ (Universidad de Buenos Aires)
}

\begin{abstract}
RESUMEN:
A partir de la ya famosa investigación de Antonello Gerbi sobre la "disputa" acerca de la naturaleza de América, exploro los discursos a favor y en contra de la idea de una naturaleza corrupta en la temprana prensa periódica porteña. Quiero proponer que la problematización del tópico en dos publicaciones periódicas entre 1801 y 1807, presentadas como intervenciones en una polémica en verdad imposible, permitió a los letrados que en ella intervenian definir su actividad en la prensa periódica.
\end{abstract}

PALABRAS CLAVE: historia de la prensa argentina - literatura colonial argentina .

\section{Abstract:}

Building on Antonello Gerbi's now famous conceptualization of a 'dispute' on the nature of America, I explore the presence of both antiand pro-American discourses in Buenos Aires's early periodical press. I propose that the problematization of the topic in two periodical publications between 1801 and 1807, portrayed as interventions in a dispute that was actually impossible, provided the opportunity for lettered men to define themselves and their activities in the new medium.

KEYWORDS: history of Argentine Press - colonial Argentine literatura .

La América ha aparecido siempre sin poder físico ni psíquico alguno, y todavía lo hace. Guillermo Federico Hegel, Filosofía de la historia, 1832.

En su monumental ensayo La disputa del Nuevo Mundo, Antonello Gerbi ha seguido el derrotero de una idea particular sobre el continente americano combinando un estilo ameno y una erudición implacable (Gerbi 1982). ${ }^{1}$ Se trata de la tesis de que la naturaleza de América es “inferior", en distintos sentidos, a la del Viejo Mundo (es decir, el espacio conocido en las vísperas de la llegada de Colón: Europa, el norte africano y el Cercano y Medio Oriente). Si bien esta idea ya estaba presente en algunos de los primeros observadores europeos (a quienes Gerbi dedica un estudio posterior), ${ }^{2}$ habría sido el conde Jorge Luis de Buffon el iniciador de una versión "científica" de ella. Lo que Buffon y sus seguidores agregan a la visión ya existente en la segunda mitad del siglo XVIII es en realidad la concepción de la nueva historia natural, que supone una naturaleza sumergida en la historia en cambio constante, en "evolución" (sin la connotación que el término adquiere después de la teoría de Carlos Darwin). No se trata solo de una inferioridad, entonces, sino más bien de una "inmadurez" de la naturaleza americana, puesto que en el Nuevo Mundo plantas y animales sufren la detención de su desarrollo o incluso su degeneración. Guillermo Federico Hegel es el exponente más famoso de este discurso, que tuvo a Buffon y al abate Cornelio de Pauw entre sus más exitosos difusores. ${ }^{3}$ De plantear la inmadurez y degeneración de animales y plantas a encontrar los mismos problemas entre los seres humanos que habitaban el continente (inmadurez entre los nativos, degeneración entre estos y también entre los descendientes de europeos) no había más que un paso, frecuente a fines del siglo XVIII y con éxito constante durante el XIX.

Entendida así, a su vez, la tesis buffoniano-hegeliana tiene una larga existencia, contaminada o no con la "leyenda negra" de la conquista, y se cruza con justificaciones más o menos amables de la dominación colonial y los vínculos neocoloniales, con racismos y xenofobias varios, y hasta con las teorías del desarrollo, que también suponen una América detenida o retrasada en el tiempo, "fuera de la historia”. Asimismo, desde su más temprana formulación, la tesis tuvo también sus detractores, tanto entre sabios europeos que no aceptaban las ideas de sus colegas como entre letrados americanos, que a su escepticismo epistémico sumaban un orgullo local herido. 
En este trabajo, en el marco de una investigación más extensa sobre las primeras publicaciones periódicas de Buenos Aires entre 1801 y 1810, queremos dar cuenta de algunos ecos de esa disputa en estas publicaciones. Entre las numerosas "defensas" de la naturaleza y los hombres americanos, me intereso por estas no tanto para agregar un capítulo más a la larga disputa (tarea en cierta medida estéril una vez fijados sus ejes centrales, aunque sólo "en cierta medida", pues de los matices y variaciones también puede llegarse a conclusiones de interés, ya respecto de la disputa, ya de otras cuestiones de la historia intelectual), ${ }^{4}$ sino para utilizarla como una entrada más en el corpus de las publicaciones periódicas en el período tardocolonial porteño. Esta "entrada" me parece enriquecedora por, al menos, dos motivos. En primer lugar, por los escasos trabajos sobre estas fuentes que abordan la especificidad del medio (impreso periódico) y su lugar en una historia intelectual; ${ }^{5}$ en segundo lugar, porque este se halla marcado por la vocación polémica de sus autores en el período seleccionado.

Quiero explorar esta temática en el Telégrafo Mercantil, Rural, Político, Económico e Historiógrafo del Río de la Plata (1801-1802) y en el Semanario de Agricultura, Industria y Comercio (1802-1807), dos publicaciones que, pese a compartir aspectos materiales e ideológicos, tuvieron proyectos editoriales divergentes y muy diversa fortuna, tanto entre sus contemporáneos como en la historia posterior. Debido a la brevedad de este trabajo, daré algunos ejemplos de intervenciones en esta "disputa", de modo tal de dar cuenta no sólo de la recepción de debates ocurridos en otros espacios, sino también de ciertas estrategias en la construcción de una determinada figura de autor, ligadas a un orgullo local.

\section{Ecos de la disputa del Nuevo Mundo en el Telégrafo Mercantil, Rural, Político, Económico e Historiógrafo del Río de la Plata}

El Telégrafo..., publicado por Francisco Antonio Cabello y Mesa entre abril de 1801 y octubre de 1802, toma para sí la difícil tarea de crear un pblico para un medio que, pese a la llegada esporádica de periódicos europeos y americanos a Buenos Aires, no deja de ser novedoso, en tanto es una producción local (en su mayor parte) y tiene una circulación regular. ${ }^{6}$ En ese sentido, la primera aparición polémica del tema de la inferioridad americana apunta a exhibir el valor del Telégrafo... como proveedor de argumentos para refutarla. En el número 10, aparece un artículo con la firma de Patricio Colón, quien a su vez dice citar a Diego Solanze (los dos probablemente no existen y esconden la pluma del propio editor); en él, después de afirmar que el Telégrafo... se trata de un periódico "capaz de medirse con los mejores de las erguidas Cortes de Europa" y de describir sus ideas "tan vastas como nuestras Pampas y tan caudalosas como nuestros Rios", le indica al editor un curso determinado para su empresa:

si se atiene el Editor solo á Noticias Americanas, como ha ofrecido, sera su Papel buscado por todos los Europeos Sabios y por todos los Americanos curiosos [...] ¿Quanto mas os deberia la Europa ¡Ho Americanos! si en el $2^{\circ}$ termino de este Papel fuerais manifestando los Misterios del Nuevo Mundo [...]; si os rierais de quanto han dicho los Filosofos sobre el color humano [...] y si les hicierais conocer su Mundo a las gentes de instrucción [...] Finalmente, para terminarse dicho papel con amenidad y satisfaccion [...] podría llenarse el hueco con rasgos de literatura y de gusto, ya pitando un Volcan de los Andes, ya un Celage de la Mar del S. ya el salto del Rio Niagara, ya un viage ácia Quito. ¿No se mira ya elogiado por los buenos Américanos el que inserte un parrafo asegurando ser los Indios antropofagos generalmente; las petrificaciones voluntarias de la costa de Campeche; la enfermadad del pasmo y de los 7 dias; la verdura eterna de estos Campos, el cordonazo de $S$. Francisco, y otras mil cosas que los Filósofos niegan como exageraciones de Viageros? (Telégrafo... I, 10, 76-79) ${ }^{7}$

El intento de direccionar el contenido futuro del Telégrafo... se orienta entonces a ilustrar de igual modo a americanos y europeos, pero parte de la necesidad de contradecir ideas que ya circulan y se han instalado entre unos y otros. Al mismo tiempo, sin refutar explícitamente la inferioridad de la naturaleza americana, por un lado ironiza sobre las conclusiones de los "Filósofos" europeos (que llegan al punto de ser risibles) y, por el otro, propone como tema la exuberante naturaleza del Nuevo Mundo, a la que también toma como término de la comparación (las Pampas vastas y los ríos caudalosos). El planteo, que no hace explícita la 
oposición, deja claro que si la opinión sobre la inferioridad de la naturaleza americana era conocida por los lectores imaginados del Telégrafo..., también lo eran los contraargumentos usuales. ${ }^{8} \mathrm{Si}$ el proyecto europeo de sistematización de la naturaleza llevado adelante durante el siglo XVIII (el perfeccionamiento de la historia natural) creó una "conciencia planetaria eurocentrada" (Pratt, 1997: 76), la estrategia sugerida por Cabello y Mesa apunta a desbancar la naturaleza europea concebida como norma global: aquello que es común en América es visto como exageración de viajeros en Europa, lo cual delata simultáneamente la ignorancia de sus "filósofos" y la inferioridad de su naturaleza."

Una actitud similar es la asumida por el asiduo colaborador Tadeo Haenke al describir la naturaleza de diferentes partes del Virreinato: si bien no hay una discusión explícita de los argumentos de Buffon, de Pauw y sus seguidores, sí hay una exhibición de la naturaleza exuberante, fecunda y útil para el ser humano. ${ }^{10}$ Ejemplo de esto último son las exhortaciones al Estado para fomentar determinadas producciones vegetales, animales o minerales. ${ }^{11}$ Aun otros colaboradores, como Juan de Puebla, en su artículo "Quadrupedos", sin mencionar aquellos argumentos explícitamente, abrevan de ellos sin refutarlos por completo, pero sin tampoco aceptarlos ( Telégrafo III, 9, 133-135). ${ }^{12}$

Cuando ya se consideran las aristas humanas de la disputa, como ha observado Matías Maggio Ramírez, los textos insertos en el Telégrafo..., como los de otros periódicos porteños de fines de la colonia, imaginan una civilización que en verdad es escasa a las orillas del Río de la Plata, retratando la ciudad como centro de cultura y refinamiento. ${ }^{13}$ La representación de la prensa periódica como el medio ilustrado por excelencia y de la ciudad como espacio civilizado está presente en el Telégrafo... a lo largo de su corta vida. Aparecen, por ejemplo, al postular el propio periódico como escenario de polémicas en las que sujetos racionales dirimen a través del discurso las diferencias de opiniones. Pero también en la representación de la mujer americana, y más en particular porteña, como superior a las europeas en refinamiento, educación y belleza. ${ }^{14}$

\section{Ecos de la disputa en el Semanario de Agricultura, Industria y Comercio}

El Semanario..., publicado por Juan Hipólito Vieytes entre 1802 y 1807 (con una interrupción de dos meses en agosto y septiembre de 186, debida a la invasión inglesa) tenía, al igual que el Telégrafo..., un proyecto editorial que se basaba en lograr la mayor difusión posible, pero, a diferencia de aquél, centraba su temática de manera casi exclusiva en la economía, como indica su título. Si bien este proyecto fue variando con el correr del tiempo para albergar cuestiones más variadas, también fue mantenido en términos generales como eje del periódico, que aporta conocimientos de orden teórico de la economía política (que empieza a definirse como ciencia en esos añosy conocimientos prácticos, de tipo técnico, sobre cómo mejorar la producción agropecuaria y manufacturera de la campaa portea, a cuyos habitantes toma como destinatarios privilegiados. ${ }^{15}$

En relación con ello, la descripción de la naturaleza americana que aparece en el Semanario... es aun más positiva que la del Telégrafo... En tanto uno de los objetivos es fomentar la explotación agrícola, el tópico de la fertilidad inmensa de las pampas aparece repetido varias veces, haciendo énfasis también en su utilidad:

Situados en el centro de una zona templada, circundado de caudalosos Rios navegables en centenares de leguas, dueños absolutos de unas tierras que semejantes al mar forman un orizonte continuado en su extension; poseedores de unos montes asombrosos en los que se encuentra la madera mejor del universo: inundados de ganados, y de frutos preciosisimos, y colocados por último en el centro del mundo comerciante; qué nos falta para fixar de una vez el término de la mayor felicidad sino recordar de la soporacion y el sueño á que nos tiene reducidos la abundancia? ( Semanario... I, 4, 25-26)

Asimismo, la refutación de las críticas europeas del "carácter" americano es explícita y parece apoyarse en valores compartidos con el lector (o que se suponen compartidos), al punto tal que Vieytes se permite ironizar 
sobre ellos. Luego de instar a sus lectores a no tolerar "que se nos den los despreciables epitectos de perezosos e indolentes", explica en nota al pie:

Mr. William Guthrie en su Geografía universal segunda edicion del año de 1800 [...] honra á los Americanos con las expresiones siguientes: Los Criollos tienen todas las malas qualidades de los Españoles de quienes son descendientes, sin este valor, esta firmeza, y esta paciencia que forman el buen lado del carácter Español; naturalmente afeminados; ellos pasan la mayor parte de su vida en la ociosidad y los placeres. Fastuosos sin gusto, y sin elegancia, pródigos por ostentacion mucho mas que por regocijo: el amor y la intriga hacen toda su ocupacion:: Pasma á la verdad que en el siglo de la ilustracion, y de la filosofia aun se encuentren partidarios de nuestro acérrimo depresor el Sr. Paw. ¡Quando enmudecerá la maledicencia! (Semanario... I, 4, 26, subrayado en el original) ${ }^{16}$

Otro colaborador, Manuel José de Lavardén, escondido detrás del anagrama Fray Juan Anselmo Velarde, redacta unas "cartas" que son una elocuente de defensa del alto grado de desarrollo alcanzado por la colonia sudamericana. Lavardén escribe contra un artículo incluido en el Telégrafo... — según algunos, motivo de cierre del periódico-, ${ }^{17}$ en el que hombres y mujeres de Buenos Aires son tratados respectivamente como delincuentes y prostitutas. En su carta, el "fraile" insiste en desprestigiar al autor anónimo de "Politica" 18 a partir de ciertas incoherencias en su argumento (por ejemplo, en el hecho de que, según los datos aportados, habría en Buenos Aires doscientas mil mujeres o solteronas o prostitutas, una vez que se realizan los cálculos pertinentes), pero también contraponiendo hechos y datos concretos que solo le son permitidos exponer a Lavardén a partir de su "estar ahí", de su experiencia personal en la vida diaria porteña. Y aun recurre al orgullo local (y podría suponerse que a la complicidad o simpatía del lector) para indirectamente elogiar su propia escritura con la bumillitas correspondiente:

Para pocas plumas es hacer el elogio de los Señores Vecinos de Buenos-Ayres. Esta empresa es superior á mis fuerzas; pero no hago falta, pues quando todas las lenguas enmudeciesen alzarian el grito los muros de tantos Templos, Conventos, Hospitales, erigidos, dotados, sostenidos por los Españoles Europeos, en la mayor parte. (Semanario... I, 6, 48)

Es la realidad porteña, más que su pluma (que de todos modos está haciendo aquello de lo que se considera indigna), la que viene a refutar el artículo del Telégrafo... y, en general de toda crítica al Nuevo Mundo.

Por otro lado, en la misma carta está contenida la que será la respuesta general de los artículos del Semanario... al problema del conocimiento "importado": si su autor cita a Condillac, Horacio, Virgilio, Molière (confundiéndolo con German François Poullain de Saint Foix) y a Concolorcorvo, de modo tal que da cuenta de su propia preparación y lectura de los "sabios" europeos, propone que hay un saber específicamente americano, que lo hace distinto del Viejo Mundo y que con las categorías de éste no puede evaluarse la realidad porteña. Al proponerse hablar sobre la agricultura en las campañas de Buenos Aires, escribe:

Si los Arabes no hubieran quemado la Biblioteca de Ptolomeo, alli pudieramos hallar algo adaptable á nuestra situacion, del tiempo de los Reyes Pastores, si alguna vez los hubo. Los pueblos barbaros no escriben, y Paris, y Londres tienen mucha gente, y poco terreno para que sus especulaciones puedan convenir á los que tenemos mucho terreno, y poca gente. No es mi ánimo hacer un tratado universal de Economia, solo pienso tocar los puntos en que nos distinguimos del resto del mundo culturo. (Semanario... I, 7, 49-50)

Denunciando la inadecuación de las teorías foráneas, Lavardén no sólo impugna las teorías sobre la inferioridad y la degeneración americanas, sino que también da a entender que los únicos en condiciones de poder analizar y entender la realidad americana son los propios americanos. Su siguiente carta es elocuente desde su título: "Carta 2. De Fr. Juan Anselmo de Velarde, sobre las erradas prevenciones de los Extrangeros en órden á nuestra situacion económica" ( Semanario... I, 11, 81-88 y I, 12, 89-91). En ella discute con el Abate Raynal, el barón de Montesquieu, William Guthrie y con el autor de un libro referido como "Ciencia del Comercio", llamado Serra, de origen italiano, a quien se le otorga el título de "monseñor". ${ }^{19}$ A las ideas de Lavardén, Vietyes agrega una nota al pie citando un comentario inexacto de Buffon sobre la cría de vicuñas, que ridiculiza. 
Sin embargo, en el Semanario... el discurso denigratorio no sólo es impugnado abierta y explícitamente (al punto de concebirse como una tarea patriótica, como un enfrentamiento entre dos bandos), ${ }^{20}$ sino que también se cuela a veces en las opiniones de los autores criollos, actuando como una base compartida (y aceptada) de conocimientos. Así como en el periódico son frecuentes las descripciones de ciudades, caminos y otras obras que funcionan como muestra del progreso y de tierras generosas y feraces, utilísimas, son constantes las reconvenciones a los habitantes de estas, quienes son representados más de una vez como marcados por la ociosidad, la desidia y los vicios. Por ejemplo, al describir Santiago del Estero, Gabriel Antonio Hevia y Pando, un colaborador frecuente, escribe:

La Ciudad de Santiago del Estero fué fundada el año de 1562, pequeña poblacion entonces, pero en el dia menor; ¿Cómo incrementara un vecindario en donde el dueño de una casa que la ve reducida à escombros tiene por mejor pasar el resto de sus dias en una choza y en el campo que reedificarla para dexar siquiera a su posteridad y convecinos un monumento de su laboriosa existencia? [...] ¿habrá oidos tan duros á quienes no lastime oir que estas tristes victimas de la indolencia acerrimos sequazes de la destestable conducta de sus progenitores vivan como Faunos en la selva enemistados con el trato social [...]? (Semanario..., III, 124) 21

El propio Vieytes, aquel que refutaba explícitamente a De Paw y otros “depresores", escribe que "Llena está nuestra Capital, aun mas que las dilatadisimas campañas que nos cercan, de jovenes sin preocupacion y sin destino que [...] pasan sus preciosos dias en la mas lamentable ociosidad" ( Semanario... III, 118, 126), para dar sólo uno de los posibles ejemplos.

Pero no se trata de una contradicción en el discurso, sino en todo caso de diferentes mensajes para diferentes interlocutores: cuando se responde a los sabios europeos, se defiende la naturaleza y la civilización americana; cuando se habla a los habitantes de la campaña porteña, se los exhorta a dejar de lado sus características negativas que serían consideradas signos de la degeneración o la inferioridad del hombre americano por alguno de los sabios europeos. En ambos casos, sin embargo, se legitima el saber en la propia experiencia del autor, contrapuesto al de los europeos, de quienes se supone que no han tenido contacto directo con la realidad de la que hablan. Al decir de Vieytes,

Y digan lo que quisieren tantos Autores que juzgan nuestras operaciones agronomicas sin salir de su gabinete, y que creen todas las rutinas defectuosas, y poco fundadas, he visto en casi todas partes que los usos locales se fundaban en una larga experiencia. (Semanario... I, 25,190)

Se da forma así a una figura particular, la del letrado americano que funda su conocimiento (y en consecuencia su condición de letrado) en su experiencia de la realidad que lo rodea y en lo saberes importados de Europa.

\section{AMERICANOS EN LA DISPUTA}

En ese sentido, la prensa periódica de la primera década del siglo XIX porteño funcionó como el escenario en el que los "letrados patriotas", como los ha llamado Jorge Myers, pudieron constituir, al menos parcialmente, su figura pública. Según Myers, la característica central de este nuevo tipo de letrado, al que ubica entre 1780 y 1820 , es que gozó de una autonomía mayor que su contraparte colonial, a la vez que tuvo un poder mayor que su sucesor del período independiente. "Vocero" de su patria natal, su escritura está marcada estrictamente por los intereses locales; atento a los intereses locales, en tanto que letrado no deja de estar al servicio de la elite social (Myers, 2008). Y, podría agregarse, a la inversa, "vocero" de una civilización pensada como universal, apostrofa a sus compatriotas y reclama a los extranjeros su pertenencia y la de todos los americanos a la civilización.

Si Cabello y Mesa y Haenke (asturiano y bohemio, respectivamente, pero que asumen plenamente su carácter de letrados americanos), Vieytes (porteño, de San Antonio de Areco) y Lavardén (porteño), para tomar como ejemplo a los autores que hemos citado aquí, empiezan a expresar esos intereses locales y también 
un orgullo regional a la hora de exhibir el grado de civilización alcanzado por la colonia porteña y de desarrollo de la naturaleza americana, la prensa periódica, que permite y, en el caso porteño, se propone una mayor circulación de la información, es el medio en el cual se entabla una polémica cuyo interlocutor no está en condiciones de responder. Es decir, ni Buffon ni los otros pensadores europeos que habían catalogado a América como "inmadura" o "degenerada" escriben en el Telégrafo... o en el Semanario... ni, con casi total certeza, leen esos periódicos; la "disputa", en el caso rioplatense, resulta entonces una "polémica de un solo lado". Los letrados patriotas delimitan dos destinatarios para su discurso: el destinatario polémico, los sabios europeos, y el destinatario real, los lectores americanos a los que se busca ilustrar, a veces citando las ideas de aquellos que en otras ocasiones se discuten (la holgazanería del hombre americano, por ejemplo). ${ }^{22}$

Así, los autores aquí trabajados asumen para sí el lugar de defensores de América (su naturaleza y su humanidad) como estrategia de autoposicionamiento: desde un decir polémico, se ubican a sí mismos como letrados patriotas que pueden expresar la opinión de su lugar de origen. A la vez, la prensa periódica aparece como un escenario imprescindible para ese tipo de posicionamiento, apelando a un lector de textos breves pero a la vez incluidos en ese macrotexto que es cada uno de los números y el periódico en sí mismo.

\section{Periódicos}

Telégrafo Mercantil, Rural, Politico-Economico e Historiografo del Rio de la Plata, 1801-1802.

Semanario de Agricultura, Industria y Comercio, 1802-1807.

\section{FUENTES SECUNDARIAS}

Fernández Bravo, Álvaro (2004). "Catálogo, colección y colonialismo interno: Una lectura de la Descripción de la Patagonia de Thomas Falkner (1774)”, en Revista de Critica Literaria Latinoamericana 60, pp. 229-249.

Calvo, Nancy y Rodolfo Pastore (2005). "De viajeros y periodismo ilustrado: Aportes del naturalista Tadeo Haenke en el Telégrafo Mercantil del Río de la Plata (1801-1802)”, en Dieciocho, vol. 28, n² 2, pp. 23-46

Correa Luna, Carlos, Augusto S. Mallié y Rómulo Zabala (1928). “Advertencia”, en Semanario de Agricultura, Industria y Comercio, Buenos Aires, Junta de Historia y Numismática Americana, tomo I, pp. 17-27.

Díaz, César Luis (1997). "Los albores del periodismo rioplatense", Congreso Nacional de Historia Argentina bajo la advocación de los 150 años de la batalla de la Vuelta de Obligado. Buenos Aires, vol. 1, pp. 59-71.

Galván Moreno, Celestino (1944). El periodismo argentino. Amplia y documentada historia desde sus origenes hasta el presente, Buenos Aires, Claridad.

Gerbi, Antonello (1982) La disputa del Nuevo Mundo. Historia de una polémica. 1750-1900, México, Fondo de Cultura Económica.

Gerbi, Antonello (1978). La naturaleza de las Indias Nuevas. De Cristóbal Colón a Gonzalo Fernández de Oviedo, México, Fondo de Cultura Económica.

Hegel, Georg Wilhelm Friedrich (2011). "Geographical Basis of History”, Philosophy of History. Disponible en www.marxists.org, consultado el 26/4/2011, traducción propia.

Maggio Ramírez, Matías (2008). “Un puro vegetar”. En: Paulina Brunetti, Matías Maggio Ramírez y María del Carmen Grillo, Ensayos sobre la prensa, Buenos Aires, Biblioteca Nacional.

Maggio Ramírez, Matías (2009). "Civilización imaginada. Lecturas sobre civilidad e identidad en la Buenos Aires colonial en su prensa periódica”, en La Biblioteca 8, pp. 262-284.

Martínez Gramuglia, Pablo (2009). "El pensamiento agrario ilustrado en el Río de la Plata: un estudio del Semanario de Agricultura, Industria y Comercio (1802-1807)”, en Mundo Agrario 18. Disponible en http://www.mundoa grario.unlp.edu.ar/.

Martínez Gramuglia, Pablo (2010). “A la búsqueda de lectores: El Telégrafo mercantil”, en Question 27. Disponible en http://perio.unlp.edu.ar/ojs/index.php/question/index. 
Martínez Gramuglia, Pablo (2013). "Nuevos textos, nuevos (y viejos) lectores: la representación del público en los periódicos de 1801 a 1810”, Batticuore, Graciela y Gayol, Sandra (eds.). Lecturas de la cultura argentina, 1810 - 1910 - 2010. Buenos Aires, Prometeo.

Martini, Mónica (1998). Francisco Cabello y Mesa. Un publicista ilustrado de dos mundos, Buenos Aires, DunkenInstituto de Investigaciones sobre la Identidad Cultural (Universidad del Salvador).

Myers, Jorge (2008). "El letrado patriota: los hombres de letras hispanoamericanos en la encrucijada del colapso del imperio español en América”, en Jorge Myers (ed.), La ciudad letrada de la conquista al modernismo, Buenos Aires, Katz, vol. I de Carlos Altamirano (dir.), Historia de los intelectuales en América Latina, pp. 121-144.

Navallo, Tatiana (2010). “Ideas ilustradas en el Río de la Plata: de los manuscritos al 'Proiecto Geográfico' del Telégrafo Mercantil (1801-1802)”, en Tinkuy 14, pp. 159-197.

Pratt, Mary Louise (1997). Ojos imperiales. Literatura de viajes y transculturación, Bernal, Universidad Nacional de Quilmes.

Puiggrós, Rodolfo (1960). "Gerbi, Antonello, La disputa del Nuevo Mundo, México, Fondo de Cultura Económica, 1960, 682 pp”, en Revista de Historia de América 52, pp. 613-616.

Sánchez Zinny, Fernando (2008). El periodismo en el Virreinato del Río de la Plata, Buenos Aires, Academia Nacional de Periodismo.

Torre Revello, José (1956). “La biblioteca de Hipólito Vieytes”, en Historia, vol. 2, n 6, pp. 72-89.

Verón, Eliseo (1987). "La palabra adversativa. Observaciones sobre la enunciación política”, en Eliseo Verón y otros, El discurso politico. Lenguajes y acontecimientos, Buenos Aires, Hachette, pp. 11-26.

Weinberg, Félix (1956). “Juan Hipólito Vieytes, precursor y prócer de Mayo”, estudio preliminar de Juan Hipólito Vieytes, Antecedentes económicos de la Revolución de Mayo, Buenos Aires, Raigal, 1956, pp. 7-133.

\section{Notas}

1 La edición original es de 1955 y el trabajo de Gerbi ha recibido innumerables críticas, algunas de las cuales fueron tenidas en cuenta por su autor al producir su segunda edición en 1976; todavía hoy sigue dando lugar a "disputas sobre la disputa”, en parte seguramente por la perspectiva humanista y ensayística que adopta. Sin embargo, sigue valiendo el duro y acertado juicio de Rodolfo Puiggrós, apenas un año después de publicada la traducción de la primera edición: "de ahora en adelante La disputa del Nuevo Mundo será imprescindible obra de consulta [...] no obstante imponerle su vocación literaria al brillo formal el sacrificio del análisis que hubiéramos deseado más profundo y acertado, y colocarlo, en puntos fundamentales, en corrientes de pensamiento ya superadas por la historia” (1960: 613).

2 Ver Gerbi 1978.

3 Escribe Hegel en 1831-2, un par de décadas después del período que nos ocupa: “[En América del Norte] Los aborígenes han adoptado, por cierto, algunas artes y costumbres de los europeos, entre ellas la de beber licores, que ha tenido un efecto mortífero. En el Sur los nativos fueron tratados con una violencia aun mayor y empleados en trabajos exigentes, para los cuales su fuerza no era en absoluto la adecuada. Una actitud liviana y desapasionada, la falta de espíritu y la total sumisión frente al criollo, y más aun frente al europeo, son las características principales de los indígenas americanos [...]. La inferioridad de estos individuos en todos los aspectos, incluso en su tamaño, es palmaria; sólo en las razas más alejadas de la Patagonia hay algunas naturalezas más vigorosas, pero todavía permanecen en su condición natural de rudeza y barbarismo. [...] Cuando los jesuitas y los curas católicos intentaron habituar a los indios a la cultura y las costumbres europeas [...] les prescribieron las obligaciones de cada día, que, pese a su tendencia a la haraganería, cumplieron bajo la autoridad de los frailes. Estas obligaciones (a la medianoche una campana debía recordarles el cumplimiento de sus obligaciones maritales) fueron al comienzo, y muy astutamente, dirigidas a la generación de deseos [...]. La debilidad de la psique americana fue la primera razón para llevar negros a América [...], [un viajero inglés] conoció un solo un nativo cuyo intelecto fuera lo suficiente desarrollado para estudiar, pero murió poco después, por exceso de bebida" (2011: s/ p, traducción propia).

4 Significativamente, Gerbi dedica unos pocos párrafos a letrados del área rioplatense: menciona a algunos jesuitas expulsos, la decisión de Mariano Moreno de reimprimir la defensa de los americanos elaborada por Thomas Jefferson (que Gerbi analiza in extenso) y el modo en que las composiciones de La lira argentina contraponen un Mundo Nuevo que es el hogar de la esperanza y uno Viejo donde vive la opresión. Ver Gerbi 1982: 399. Más recientemente, Álvaro Fernández Bravo (2004) ha analizado bajo la luz de la disputa los escritos del jesuita Tomás Falkner. Una aproximación 
interesante al problema en la prensa periódica puede hallarse en Maggio Ramírez 2009. También toca el tema, aunque no es el centro de su estudio, Navallo 2010.

5 Para visiones de conjunto del periodismo tardocolonial, se pueden consultar Galván Moreno 1944, Díaz 1997; y Sánchez Zinny 2008.

6 Para una caracterización general, completa y actualizada del Telégrafo..., ver Martini 1998. En relación con la problemática de sus lectores, ver Martínez Gramuglia 2010 y 2013.

7 Para citar los periódicos indico tomo en números romanos, número en arábigos y números de página. Estos responden a la organización en tomo, no a cada número.

8 Escribe Matías Maggio Ramírez: "las referencias a Guthrie, Buffon, de Pauw en el corpus colonial sirven para pensar la circulación de aquéllos [sus libros] entre los lectores de la élite porteña. Las menciones en los periódicos evitaban presentaciones de los eruditos europeos, se los trataba como si fueran un viejo conocido, al marcar así que operan como un marco de referencia compartida ante el cual se reacciona" (2009: 279).

9 El discutido estudio de Mary Pratt argumenta en un sentido similar en el capítulo 8, "La reinvención de América / La reinvención de Europa: la autoformación criolla” (1997: 301-342). Allí, partiendo cronológicamente de la década de 1820, con la publicación de "La agricultura en la zona tórrida" de Andrés Bello, "Mi delirio en el Chimborazo" de Simón Bolívar y "En el teocalli de Cholula” de José María Heredia, la autora canadiense liga el "estilo forzadamente americanista” (p. 304) con la construcción de una literatura cívica que reafirma las identidades nacionales en formación, dando lugar a "representaciones criollas como una transculturación de materiales europeos, que eran seleccionados y desplegados en forma que no reproducía simplemente las visiones hegemónicas de Europa...” (pp. 325-326). Los textos aquí analizados están lejos de plantear una identidad nacional o continental en términos políticos, como ocurriría después de las revoluciones de independencia, pero sí exhiben lo que hemos denominado un "orgullo local", a partir tanto de la exuberancia natural como del grado de progreso humano.

10 Son varios los artículos enviados por Haenke al Telégrafo... Ver Telégrafo... I, 22, 172-174; I, 23, 177-178; I, 27, 209-213; I, 28, 217-220; I, 29, 225-228.; I, 30, 233-235; I, 32, 252-254; I, 34, 264; II, 18, 126-128; II, 19, 144-148; II, 29, 209-211; II, 36, 289-295; III, 7, 103; III, 10, 137-144; III, 11, 153-155; V, 1, 1-3. Para un análisis completo de la obra de Haenke en el Telégrafo..., ver Calvo y Pastore 2005, y también Navallo 2010.

11 Por ejemplo, "Me he propuestao de exponer en esta obrita, con el posible orden método, las mas interesantes de ellas [las producciones] como parte de los frutos de mis dilatados y penosos viages, dignas en toda consideracion de la atencion del Estado, quien de su fomento y proteccion, con el tiempo, podrá sacar las mayores ventajas, como de unas substancias que son las primas materias, los Elementos, y la Base fundamental de todas las obras industriables manufacturas y Artes". Telégrafo... I, 23, 178.

12 El artículo es parte de una serie que describe la naturaleza de la campaña porteña, comparándola con España y el resto de América, en algunos aspectos de manera favorable y en otros no. La redacción de este en particular deja ver que se apoya en las ideas (si no necesariamente en los textos) de Buffon: "Las especies de Quadrupedos que hay en el districto de este Gobierno desemejantes á las que vemos en el antiguo emisferio, son muy pocas y lo mismo sucede con las demas clases, aun que degeneradas" (p. 133, subrayados nuestros).

13 La hipótesis central de Maggio Ramírez es que la difusión del discurso civilizatorio en Buenos Aires a través de la prensa periódica fue simultánea a la consolidación de una identidad local (enfrentada en un comienzo a las potencias europeas "no amistosas" - Francia, Inglaterra - y, a partir de 1806, gradualmente también a la metrópoli española) en los mismos textos.

14 Por ejemplo, Narciso Fellovio Canton (seudónimo de Cabello y Mesa) publicó su "Elogio a las porteñas". Se lee allí que las porteñas "uniendo las prendas del espiritu á las del corazon, la facilidad de aprehender con la aplicación á instruirse cada dia mas por medio de una educacion sabia, hacen a la verdad progresos tan rapidos que no solo poseen, por sus principios, el nativo idioma, sino que se produ[c]en, leen, y escriben con admirable propiedad, exactitud y coreccion [...]. En efecto, ¿qué cosa habrá mas digna de nuestras alabanzas, que el uso de las bellas prendas del espiritu, hermanadas con los sentimientos mas nobles de la virtud, y la aplicación en una alma verdaderamente elvada? ¿Y privaremos á la Nacion de noticias tan agradables, é interesantes? ¿Reservaremos solo á la posteridad la gloria de escribir tan raras perfecciones? No, publíquelas el Telégrafo. Aberguencense las damas Inglesas, de quien un Folleto de su Corte, intitulado: Carta á una Casada, se explica asi: es estraño que en Inglaterra, aun entre las Señoras de condicion, apenas se halla una entre mil que sepa leer correctamente, y que entienda bien su lengua" (Telégrafo... II, 20, 163-164, subrayados en el original). Estas opiniones, con todo, contrastan con otras que censuran fuertemente la moral de las porteñas, como la conocida "Satirilla festiva" en Telégrafo... III, 3, 39-40.

15 Para una caracterización del Semanario..., ver Weinberg, 1956: 7-133, Maggio Ramírez, 2008 y Martínez Gramuglia, 2009.

16 El autor con quien discute, William Guthrie, había publicado una monumental geografía de doce tomos. La primera edición en castellano, titulada Geografía universal, descriptiva, histórica, industrial y comercial de las cuatro partes del mundo, es de 1806 (Madrid, Imprenta de Villapando) y la edición original (A New Geographical, Historical, and 
Commercial Grammar: and Present State of Several Kingdoms in the World) es de 1770; en 1801 se publica la décimo octava edición en inglés, por lo que muy probablemente Vieytes haya leído una especie de resumen francés, Abrégé de la géographie de Guthrie, fait sur la second edition anglaise (París, Hyacinthe Langlois) publicada en 1800 y referida como "segunda edición" (primera traducción). En la lista de los libros que fueron incautados a Vieytes en 1815 no figura ninguna de estas ediciones; sí figura una "Historia natural de Boufon en castellano" y la "Historia de la Tierra y de la Naturaleza animada”, de Oliver Goldsmith, texto publicado en 1774 que sigue de cerca las ideas de Buffon. Ver Torre Revello, 1956.

17 Ver Correa Luna et al., 1928.

18 El título completo del artículo era "Politica. Circunstancias en que se halla la Provincia de Buenos-Ayres, é Islas Malbinas, y modo de repararse", Telégrafo..., V, 2, 21-27.

19 No he podido ubicar esta obra, podría tratarse de Jacques Dupuy de la Serra, Trattato delle Lettere di Cambio secundo l'uso delle più celebri Piazze d'Europa (Venecia, 1772). Es una traducción del francés y en la portada se alude a su autor como "monsieur", tal vez de allí el "monseñor" que usa Lavardén.

20 En uno de sus artículos, Vieytes escribe: “¿Qué dirán los partidarios de Paw, de Guthrie y de todos aquellos que tienen interez en deprimirnos...” (Semanario..., I, 37, 191)

21 El artículo se continúa otro cuyo título es "Causas del atraso de las cinco Ciudades de la carrera de Buenos Ayres al Perú, y de los medios que se podian poner en uso para su adelantamiento".

22 Esta "multidestinación” tiene cierta semejanza a la establecida por Eliseo Verón para el discurso político (ver Verón 1987). En tanto el discurso político plantea siempre un adversario, se trata de una enunciación polémica que crea tres destinatarios: 1) un contradestinatario, el enemigo con quien la relación es de "inversión de la creencia": lo que es verdad para el enunciador es falso para el contradestinatario y a la inversa; 2) un prodestinatario, con quien se comparten las creencias y que pertenece a un mismo "colectivo de identificación", con quien el enunciador forma un nosotros; 3 ) por último, hay un paradestinatario, que es esencial en el juego político democrático, pues se trata del receptor de todo intento de persuasión. Si el primero se define por la inversión de la creencia y el segundo por su presuposición (el enunciador de un discurso político sabe o presupone lo que piensan sus partidarios), el paradestinatario está marcada por una "suspensión de la creencia" (Verón, 1987: 16-17).

Estos conceptos de Verón, quien parte de intuiciones sugeridas por la observación del discurso político antes que de un marco teórico general, pueden parecer extemporáneos para leer un discurso entre ensayístico y periodístico a comienzos del siglo XIX americano. Sin embargo, los referimos aquí pues la relación con la polémica de un solo lado sobre la naturaleza y la civilización americana es mucho más cercana que "cierta semejanza”. En primer lugar, siguiendo la idea de Verón de que la multidestinación define el discurso político de modo exclusivo y excluyente ("Podemos decir que el imaginario político supone no menos de dos destinatarios: un destinatario positivo y un destinatario negativo. El discurso político se dirige a los dos al mismo tiempo. Conviene subrayar que esta hipótesis no tiene mayor interés salvo que se insista en su pretensión de especificidad. Esta pretensión implica que la hipótesis sólo se aplica al discurso político”; 16), su presencia nos estaría dando cuenta de, al menos, un contenido político - ya que no un discurso específicamente político- en la textualidad del Telégrafo... y del Semanario... Y, en segundo lugar y tal vez de modo más significativo, la presencia en esa textualidad de un contradestinatario y un paradestinatario y la ausencia de un prodestinatario indican una apelación al tribunal de la opinión pública cuya imagen pivotea entre un imaginario de Antiguo Régimen y uno específicamente moderno. Sin caer en el error de considerar el discurso polémico o el discurso suasorio como exclusivamente "moderno", en esa apelación a una opinión pública podemos ver hasta qué punto la prensa periódica de comienzos del XIX se separa de una concepción del mundo tradicional. Algo de eso sugiere también la ligazón esencial que Verón supone entre la presencia de un paradestinatario en los discursos políticos y las democracias parlamentarias occidentales. 